\title{
Perceived Nursing Students' Satisfaction and Self-Confidence towards the Elements of Clinical Simulation Design and Educational Practice during the Outbreak of COVID-19 Pandemic
}

\author{
Asmaa Ghareeb Mohamed ${ }^{1}$, Lobna Khamis Mohamed ${ }^{2}$ \\ ${ }^{1}$ Assistant Professor of Community Health Nursing, Faculty of Nursing, Assiut University, Egypt \\ ${ }^{I}$ Associate Professor of Nursing Department, College of Applied Medical Sciences, UHB, KSA \\ ${ }^{2}$ Assistant Professor of Nursing Services Administration, Faculty of Nursing, Tanta University, Egypt
}

Correspondence: Lobna Khamis Mohamed; Email: lobna.ibrahim@nursing.tanta.edu.eg; Address: Faculty of Nursing, Tanta University, Egypt.

\section{Abstract:}

COVID-19 pandemic represents a challenge not only to frontline health professionals, who introducing nursing services but also to nursing academics in nursing education. Clinical simulation is a valuable tool for teaching and learning in nursing education especially in this crisis. Aim: The study aimed to identify the perceived nursing students' satisfaction and selfconfidence towards the elements of clinical simulation design and educational practice during the outbreak of COVID-19 pandemic. Methods: A quantitative descriptive cross-sectional design was utilized. The study was conducted at the nursing department, College of Applied Medical Sciences affiliated to the University of Hafr Al-Batin. This study involved 118 nursing students who were enrolled in different levels of academic years. The questionnaire involved three instruments; the Simulation Design Scale, Educational Practices Questionnaire, and Student Satisfaction / Self- Confidence in Learning Scale. Results: The findings revealed that around half of nursing students had a low level of satisfaction with simulation activity and the highest percent of them had a high level of self-confidence for managing the simulated situations. Conclusion \& Recommendations: The study findings reflected that the use of simulation in presence of design elements and educational practices' features is a typical solution for clinical nursing education to promote students' satisfaction and self-confidence in learning. The study recommended incorporating virtual clinical simulation and other adaptive digital learning methods as a teaching strategy in nursing curricula, as well as encouragement the nursing colleges to allocate budget for purchasing equipment and high fidelity patient simulation manikins.

Keywords: Clinical simulation, COVID-19, education practice, nursing education, satisfaction, simulation design, self-confidence. 


\section{Tanta Scientific Nursing Journal}

\section{Introduction}

Recently, an outbreak of a novel coronavirus infection (SARS-CoV-2) has emerged and quickly invaded all over the world to humans, creating a major threat to global health problems and the economy ${ }^{[1]}$. The symptoms of this infection vary from mild as fever, headache, fatigue, exhaustion, and dry cough to extreme as dyspnea, diarrhea, pneumonia, and kidney failure ${ }^{[2]}$.

COVID-19 has already disrupted universities and academic institutions; especially nursing schools face unique challenges for developing the next generation of care providers ${ }^{[3]}$. This pandemic obligated a halt in the access of nursing students to clinical training placements that caused trouble to complete the planning of the learning process for the nursing curriculum. Factually, this pandemic will change the educational landscape forever ${ }^{[1,2]}$.

Simulation has been used widely in the clinical training of health-care students and professionals. It is a valuable strategy for teaching, learning, and evaluating clinical skills at different levels of nursing within a safe environment ${ }^{[4]}$. It is an active pedagogical strategy that helps nursing students to consolidate knowledge, develops technical and relational skills, as well as creates rules and habits for thinking and reflection ${ }^{[5]}$. Clinical simulation has a positive impact on nursing education (students, educators) and health organizations (individuals, groups, and communities). The principal aims of simulation as a teaching method are to improve the quality of care and ensure patients' safety ${ }^{[6]}$.

The clinical simulation was used to simulate real-life situations to encourage the nursing students to gain experience in practice and learn the requisite clinical nursing skills ${ }^{[7,8]}$. There are several models of simulation used in nursing education including; full-body mannequins, task trainers, standardized simulated patients, virtual or computer-generated simulation, or hybrid simulation to facilitate learning that ranked from low to high fidelity ${ }^{[1,9]}$. The use of simulation provides the essential elements of a reflective practitioner's future education through active participation, team collaboration, communication, repetition, and evaluation ${ }^{[10]}$.

Nursing education has been transferred from a hospital-based training model where the regular experience of tasks and procedures is highlighted to a simulation based preparation that learn students to think critically for finding out the evidence judiciously ${ }^{[11]}$. The responsibility of nurse educators is to 


\section{Tanta Scientific Nursing Journal}

prepare nursing students who can face various challenges during their entry into the practice of the healthcare field ${ }^{[12]}$. With clinical simulations, nursing students can be competent, confident, knowledgeable, and satisfied when applying nursing knowledge and skills to stressful situations without interaction with patients in a controlled learning environment ${ }^{[13,14]}$.

The National League for Nursing (NLN) Jeffries simulation theory $(2015)^{[15]}$ describes the three components of clinical simulation involving; simulation design, educational practices, and learners' outcomes that should be adhered to the planning and implementation of simulation experiences to achieve high-level outcomes. The design elements involve objectives, support, problem solving, feedback (debriefing), and fidelity (realism) of the simulation. It decides the basic objectives and physical/conceptual fidelity that guide the selection criteria of activities and scenario(s).

The features of educational practices comprise experiential, interactive, and collaborative learning. This environment requires the establishment of trust and shared responsibility between both the facilitator and learner ${ }^{[12,}{ }^{15]}$. While the structure of outcomes focuses on learners' reaction (satisfaction, self-confidence), learning (changes in knowledge, performance skills, attitudes), and behavior (how learning transfers to the clinical environment), which influence the nursing students' critical thinking, problem-solving capabilities, and clinical judgment skills ${ }^{[8,}$ $12,16]$.

On literature review, learners' selfconfidence is the degree, to which the learner believes to do what is expected of them, understands the patient care process, make appropriate care decisions without any doubt or errors ${ }^{[15-17]}$. The major sources for building self-confidence among learners are performance accomplishments (learning through personal experience), vicarious experience (learning through observation), verbal persuasion (persuasive people that their tasks finished successfully), and emotional arousal (influence people's perception $)^{[18]}$.

On the other side, nursing students' satisfaction is an important element for assessing their motivation, contentment, and acceptance with teaching strategy ${ }^{[19]}$. It is the degree to which the learner can provide maximum service with a positive attitude, remain patient-centered, and proves the teamwork skills in the multifaceted health care settings ${ }^{[17,20]}$. 


\section{Significance of the problem}

The pandemic of COVID-19 represents a challenge not only to frontline health professionals who introducing nursing services to patients but also to nursing academics in nursing education. Currently, nursing education is confronting several challenges locally as well as internationally. Likewise, the closure of universities and the cancellation of hospitalbased training due to the COVID19 pandemic, which necessitates the academicians to seek new alternatives of teaching strategies.

Consequently, nurse educators have an opportunity for adjusting simulationbased education to this exceptional situation using emerging technologies. Thus, this research aimed to identify the elements of simulation design and features of educational practices in the clinical simulation associated with nursing students' satisfaction and self-confidence in managing activities.

\section{Aim of the study}

The study aimed to identify the perceived nursing students' satisfaction and self-confidence towards the elements of clinical simulation design and educational practice during the outbreak of COVID-19 pandemic.

\section{Research's questions}

1. What is the nursing students' perception for the presence of simulation design and educational practices' elements that implemented during clinical simulation?

2. What are the perceived nursing students' satisfaction and self-confidence after passing the clinical simulation experience during COVID-19?

3. What are the relationships between nursing students' satisfaction / selfconfidence and simulation design/educational practice?

\section{Methodology}

\section{Theoretical framework:}

This study utilized the Nursing Education Simulation Framework (NESF) of Jefferies (2012) ${ }^{[16]}$ as a framework, which contains different variables affecting the simulation experience; simulation design characteristics, educational practices, facilitators' characteristics, students' characteristics, and simulation outcomes as illustrated in figure (1).

Study design: A descriptive cross-sectional and correlational study design was applied. Setting: The study was conducted in the nursing department of Applied Medical Sciences College (CAMS) at the University of Hafr Al-Batin (UHB) during the second semester of the academic year 2019-2020. 


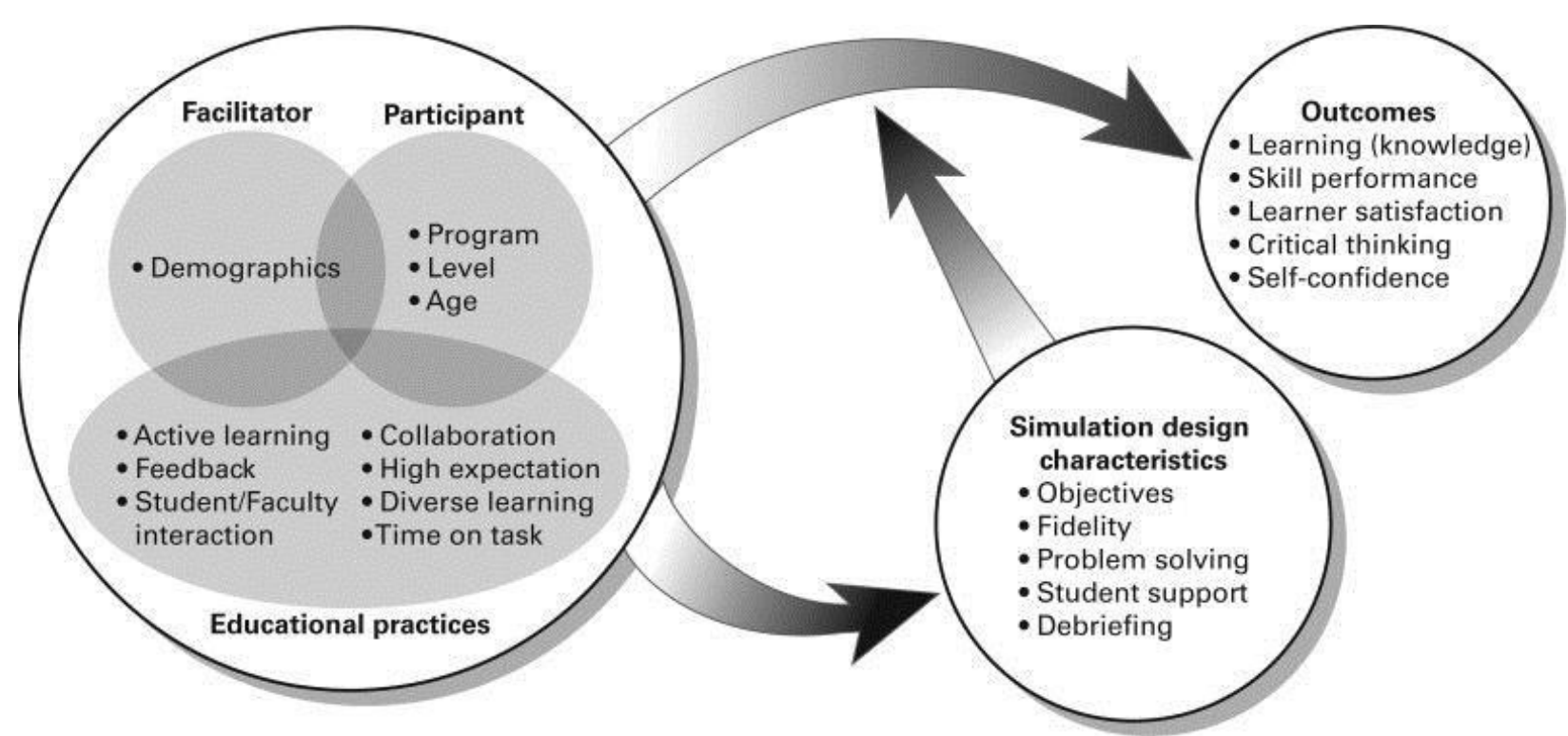

Figure 1. The Nursing Education Simulation Framework (NESF)

Source: Jefferies (2012). Simulation in nursing education: From conceptualization to evaluation

Subjects: The nursing students from freshmen, sophomore, junior, senior, and internship year were assumed in this research. The inclusion criteria involves that the students must be had an experience with lab or virtual clinical simulation training for at least one level and accepted to participate in the study. The study sample was calculated using the Thompson $(2012)^{[21]}$ equation with the following formula:

$$
n=\frac{N \times p(1-p)}{\left.\left.\| N-1 \times\left(d^{2} \div z^{2}\right)\right]+p(1-p)\right]}
$$

Where $\mathrm{n}=$ Sample size $(131), \quad \mathrm{N}=$ Population size (200), $Z=$ Confidence level at $95 \%$ (1.96), d= Error proportion (0.05), $\mathrm{p}=$ Proportion $(50 \%)$. A total number of sample was 118 nurse students who were enrolled during data collection time with a response rate of $90.1 \%$.
Tools:

The questionnaire was prepared after an in-depth review of related literature. It includes the socio-demographic characteristics of nursing students involving; age, sex, marital status, grade point averages (GPA), academic level, number of students in clinical simulation (lab or virtual), and number of studied courses via simulation, which were developed by the researchers. The study's instruments were developed by the National League for Nursing (2006) ${ }^{[22]}$ and adopted by the researchers. The researchers have taken permission for using these instruments. The three instruments are selfreported of nursing students' perceptions of simulation-based learning, which include the following scales: 
1. Simulation Design Scale (SDS): It consists of 20-items dividing into five elements; objectives / information (5items); support (4-items); problem solving (5-items); feedback (4-items); and fidelity (2-items). This scale was used to measure the presence of simulation design elements in instructordeveloped simulations.

\section{Educational Practices Questionnaire} (EPQ): It comprises 16-items distributing into four educational practices; active learning (10-items), collaboration (2-items), diverse ways of learning (2-items), and high expectations (2-items). This scale was used to measure the presence of educational practice features in instructor-developed simulations.

\section{Student Satisfaction / Self-Confidence}

in Learning (SSSCL): It incorporates 13-items to measure the student's satisfaction (5-items) and self-confidence (8-items). It is used to measure the students' self-confidence in managing the simulated patient's situations and their satisfaction with the simulation activities. The participants' responses for the three instruments were ranged from $5=$ strongly agree to $1=$ strongly disagree.

\section{Scoring system}

The students' score of simulation design ranged from 20 to 100 , while the educational practice ranged from 16 to 80 . The availability of simulation design and educational practice elements present when the nursing students' total score $\geq 60$ and not present when the total score $<60$. On the other hand, the scoring system used for determining the nursing students' levels of satisfaction and self-confidence was through the following mean score values (Pimentel, 2010) ${ }^{[23]}$ :

- High level ranged from 3.40 - 5.00 (68\% - $100 \%$ )

- Moderate level ranged from 2.60-3.39 $(52 \%-67.9 \%)$

- Low level ranged from 1:00 to 2.59 (20\% $-51.9 \%)$

\section{Validity and reliability:}

A panel of five experts was invited to review the instruments from nursing administration and community specialties to assess the face and content validity. Based on the prior revision, the required modifications have been made.

A pilot study was carried out on $10 \%$ of nursing students $(n=12)$ who were excluded from the study's sample to estimate the clarity of the questionnaire. It was conducted two times after two weeks of separation to be sure of the applicability and 


\section{Tanta Scientific Nursing Journal}

consistency of the participants' answers. The Cronbach's coefficient alpha values of the simulation design scale, educational practice scale, and student satisfaction/selfconfidence questionnaire were $0.92,0.89$, and 0.98 respectively. Additionally, the lowest testretest reliability value of the three instruments was 0.83 .

\section{Procedure:}

A structured self-administered questionnaire was translated into the Arabic language to be clear and understandable for different participants' level of education. After explaining the study's aim, the researchers contacted the students via their WhatsApp application and invited them to participate in the study via an electronic link with a questionnaire. Each participant took approximately 10 to 15 minutes to fill the questionnaire. The data collection period starts from the beginning of May 2019 until mid of July 2019.

\section{Ethical Considerations:}

Before conducting the study, approval was obtained from the authoritative personnel of the CAMS at UHB. After explaining the study's aim, written consent was gained from nursing students at the beginning of the on-line questionnaire. The students were assured that their answers would be kept confidentially and do not affect or interfere with their evaluation. The students were informed that their involvement in this research was voluntary, anonymity and no penalty would arise from withdrawal or nonparticipation.

\section{Statistical analysis:}

Data were analyzed using the Statistical Package of Social Sciences (SPSS) Version 21. Descriptive statistics and inferential statistics were carried out. Moreover, quantitative variables were described by the Mean and Standard Deviation (SD). Qualitative variables were described by percentages. Pearson's Chisquare test was conducted to observe and quantify an association between different variables. All calculated P-values were twotailed, with $\mathrm{p}<0.05$ considered as statistically significant.

\section{Results}

Table 1 reveals the frequency and percentage distribution of nursing students' demographic characteristics (No. 118). The majority of participants $(90.7 \%)$ were in the age group $20-<25$ years old with a mean score of $23.02 \pm 0.99$, and $81.3 \%$ of them were single. It was observed that $23.7 \%$ of students were in the internship academic year, $33.9 \%$ of them were in the seventh 


\section{Tanta Scientific Nursing Journal}

level, and $50 \%$ of them had a 3-<4 GPA group with a mean score of 3.05 \pm 2.01 .

Additionally, $47.5 \%$ of students reported that the number of students in the clinical simulation was ranged in 15-20 group with a mean score of $17.90 \pm 7.38$, and $54.2 \%$ of them had studied simulation courses in 5-<10 group with a mean score of $6.09 \pm 3.98$.

Figure 2 illustrates the mean scores of nursing students' perception of simulation design elements. It was apparent that the feedback/guided reflection subscale had received the highest mean score of (3.32), followed by the support subscale (3.29), then the objectives and information subscale (3.24), after that the problem solving (3.23). Finally, the fidelity (Realism) subscale has the lowest mean score (2.95).

Figure 3 displays the mean scores of nursing students' perception of educational practice elements. The figure declared that the highest mean score of educational practice features among nursing students was collaboration $(3.36 \pm 1.22)$, followed by high expectations ( $3.33 \pm 1.22)$, then using of diverse ways of learning (3.32 \pm 1.22$)$, and finally encouragement of active learning $(3.31 \pm 1.21)$.
Figure 4 represents the nursing students' perception of the presence of simulation design and educational practices' elements. It was apparent that the highest percent $(68.60 \%)$ of students felt the presence of simulation design elements, while more than half $(57.60 \%)$ of them did not feel the presence of educational practice elements.

Table 2 states the frequency and percentage distribution of nursing students' satisfaction and self-confidence. It was observed that the total mean score for SSSC was 3.27 for the satisfaction subscale and 3.41 for the self-confidence subscale. Concerning satisfaction with current clinical simulation, the results revealed that $62.8 \%$, $60.2 \% \& 55.9 \%$ of students were satisfied with enjoying how their instructor taught the simulation $(M=3.41)$, encouraging it as a variety of learning materials in all aspects of the nursing curriculum $(\mathrm{M}=3.34)$ and preferring it as a way of learning respectively $(\mathrm{M}=3.25)$.

While regarding self-confidence, the highest percentages of participants $(66.6 \%$, $67.8 \%$, and $67.8 \%$ ) felt confident of knowing how to get help when they do not understand the concepts covered in the simulation $(\mathrm{M}=3.5)$, learning what they need to know from it $(M=3.5)$, and aware 


\section{Tanta Scientific Nursing Journal}

that simulation is the instructor's learning. There were no statistically responsibility during class time $(\mathrm{M}=3.49)$.

Figure 5 declares the nursing students' perception of clinical simulation satisfaction levels. The figure showed that more than half $(59 \%)$ of nursing students had a moderate level of clinical simulation satisfaction, $32 \%$ of them had a poor level and only $9 \%$ of them had a high level.

Figure 6 declares the nursing students' perception of clinical simulation self-confidence levels. The figure revealed that $61.9 \%$ of nursing students had a high level of clinical simulation self-confidence, $32.7 \%$ of them had a low level and only $14.4 \%$ of them had a moderate level.

Table 3 represents the correlation between students' demographics data with simulation design, educational practices, and student satisfaction/self-confidence in significant differences between students' demographic data and all items of simulation design, educational practices, and student satisfaction/self-confidence.

Table 4 clarifies the correlation between nursing students' perceptions of simulation design, educational practices, and student satisfaction/self-confidence in learning. It was observed the existence of highly significant correlations between all elements of simulation design (SDS) and educational practices (EPQ) $(0.914,0.000)$, as well as between simulation design (SDS) and student satisfaction/self-confidence in learning (SSSCL) $(0.808,0.000)$ where p. at $<0.001$ level. Furthermore, there were significant correlations between elements of educational practices (EPQ) and student satisfaction/self-confidence in learning (SSSCL) $(0.902,0.000)$ at the level of .001. 
Table 1: Frequency and percentage distribution of the nursing students' demographic characteristics (No. 118)

\begin{tabular}{|c|c|c|}
\hline \multirow{2}{*}{ Variable } & \multicolumn{2}{|c|}{ Total No. $=118$} \\
\hline & No. & $\%$ \\
\hline \multicolumn{3}{|l|}{ Age: } \\
\hline$<20$ & 6 & 5.1 \\
\hline $20-<25$ & 107 & 90.7 \\
\hline $25 \geq$ & 5 & 4.2 \\
\hline Mean \pm SD & \multicolumn{2}{|c|}{$23.02 \pm 0.99$} \\
\hline Marital status: & & \\
\hline Single & 96 & 81.3 \\
\hline Married & 22 & 18.6 \\
\hline \multicolumn{3}{|l|}{ Academic year: } \\
\hline Freshmen & 14 & 11.9 \\
\hline Sophomore & 24 & 20.3 \\
\hline Junior & 25 & 21.2 \\
\hline Senior & 27 & 22.8 \\
\hline Internship & 28 & 23.7 \\
\hline \multicolumn{3}{|l|}{ Academic Level: } \\
\hline Second & 21 & 17.8 \\
\hline Third & 17 & 14.4 \\
\hline Fourth & 7 & 5.9 \\
\hline Fifth & 22 & 18.6 \\
\hline Sixth & 11 & 9.3 \\
\hline Seventh & 40 & 33.9 \\
\hline \multicolumn{3}{|l|}{ GPA: } \\
\hline$<2$ & 4 & 3.4 \\
\hline $2-<3$ & 33 & 28 \\
\hline $3-<4$ & 59 & 50 \\
\hline $4 \geq$ & 22 & 18.6 \\
\hline Mean \pm SD & \multicolumn{2}{|c|}{$3.05 \pm 2.01$} \\
\hline $\begin{array}{l}\text { No. of students in clinical simulation (lab or } \\
\text { virtual): } \\
<15 \\
15-20 \\
20 \geq\end{array}$ & $\begin{array}{l}16 \\
56 \\
46\end{array}$ & $\begin{array}{c}13.6 \\
47.5 \\
39\end{array}$ \\
\hline Mean \pm SD & \multicolumn{2}{|c|}{$17.90 \pm 7.38$} \\
\hline $\begin{array}{l}\text { No. of studied Courses via simulation: } \\
<5 \\
5-<10 \\
10 \geq\end{array}$ & $\begin{array}{l}14 \\
64 \\
40\end{array}$ & $\begin{array}{l}11.8 \\
54.2 \\
33.9\end{array}$ \\
\hline Mean \pm SD & \multicolumn{2}{|c|}{$6.09 \pm 3.98$} \\
\hline
\end{tabular}




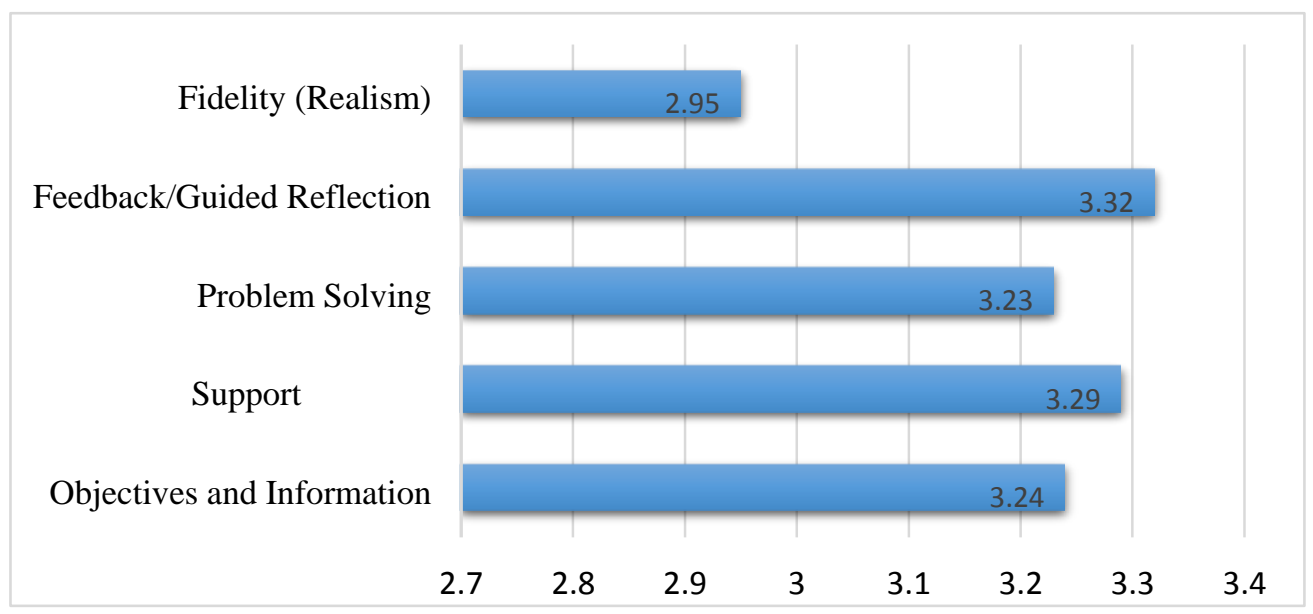

Figure 2: Mean scores of nursing students' perception of simulation design elements

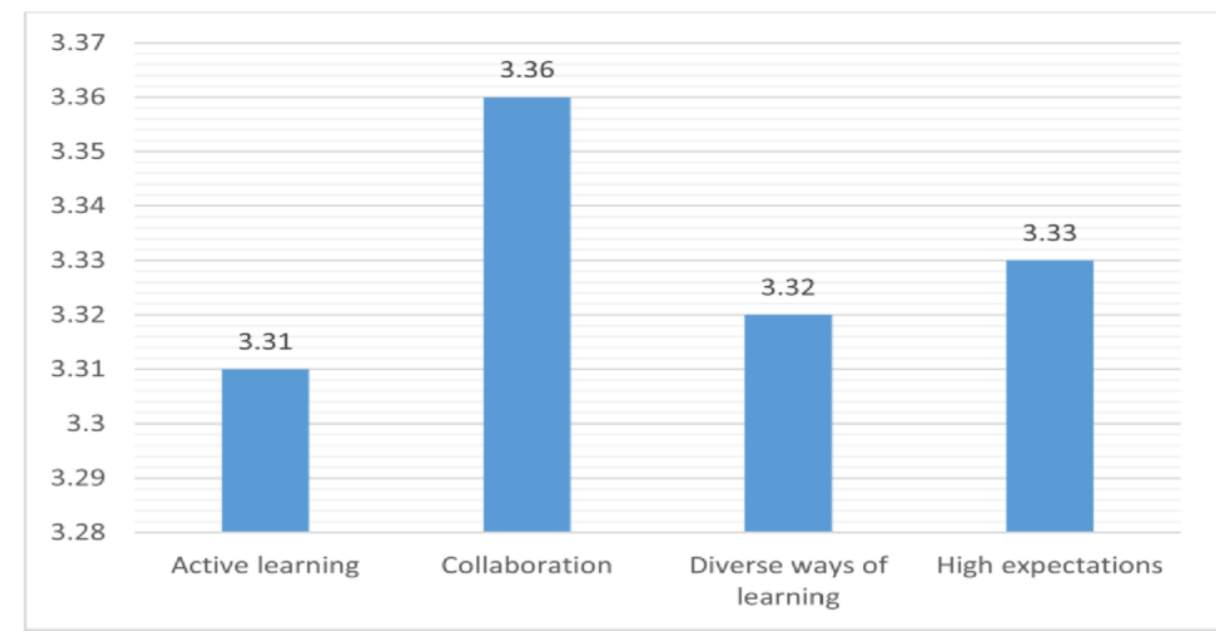

Figure 3: Mean scores of nursing students' perception of educational practice elements

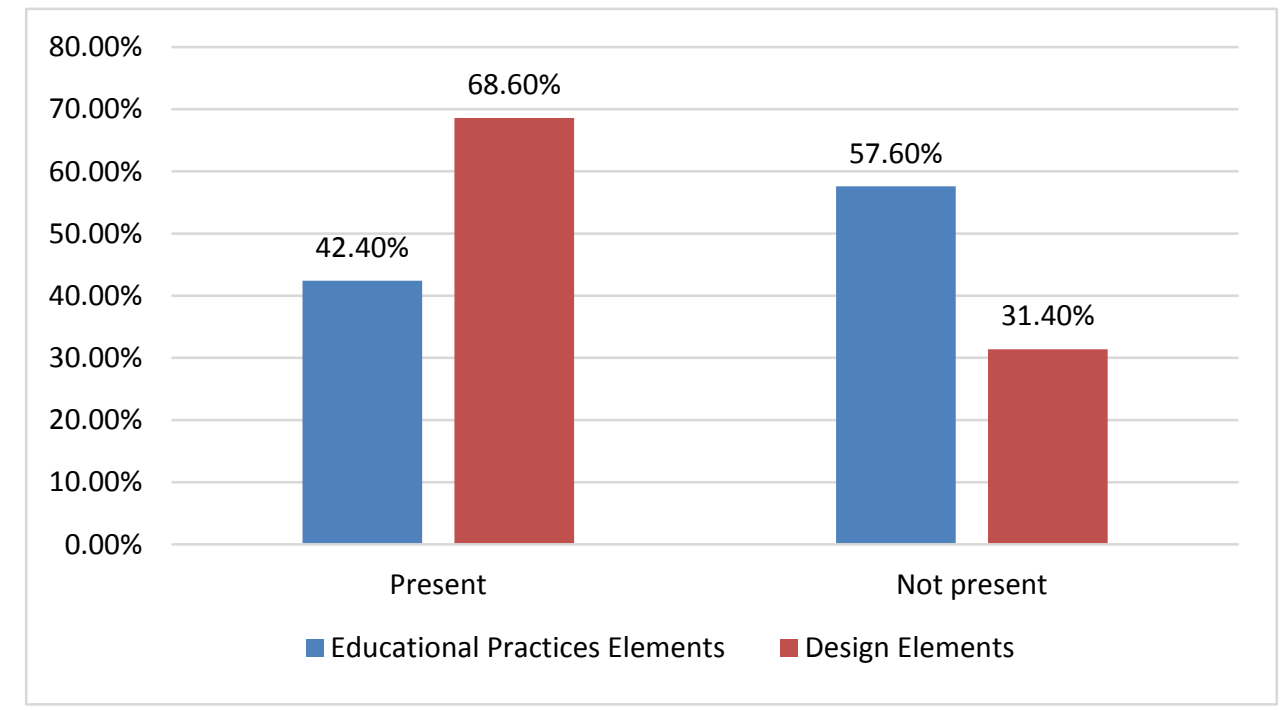

Figure 4: Nursing students' perception for presence of simulation design and educational practices' elements 
Table 2: Frequency and percentage distribution of nursing students' satisfaction and self-confidence

\begin{tabular}{|c|c|c|c|c|c|c|c|}
\hline \multirow[t]{2}{*}{ Statement } & $\begin{array}{l}\text { Strongly } \\
\text { Disagree }\end{array}$ & Disagree & Undecided & Agree & $\begin{array}{c}\text { Strongly } \\
\text { Agree }\end{array}$ & \multirow[t]{2}{*}{ Mean } & \multirow{2}{*}{ SD } \\
\hline & No. $(\%)$ & No. $(\%)$ & No. $(\%)$ & No. $(\%)$ & No. $(\%)$ & & \\
\hline \multicolumn{8}{|l|}{ Satisfaction with a current clinical simulation } \\
\hline $\begin{array}{l}\text { The teaching methods used in this simulation were } \\
\text { helpful and effective. }\end{array}$ & $\begin{array}{c}23 \\
(19.5 \%)\end{array}$ & $\begin{array}{c}15 \\
(12.7 \%)\end{array}$ & $\begin{array}{c}16 \\
(13.6 \%)\end{array}$ & $\begin{array}{c}50 \\
(42.4 \%)\end{array}$ & $\begin{array}{c}14 \\
(11.9 \%)\end{array}$ & 3.14 & 1.34148 \\
\hline $\begin{array}{l}\text { The simulation provided me with a variety of } \\
\text { learning materials and activities to promote my } \\
\text { learning in all aspects of the nursing curriculum. }\end{array}$ & $\begin{array}{c}15 \\
(12.7 \%)\end{array}$ & $\begin{array}{c}15 \\
(12.7 \%)\end{array}$ & $\begin{array}{c}17 \\
(14.4 \%)\end{array}$ & $\begin{array}{c}57 \\
(48.3 \%)\end{array}$ & $\begin{array}{c}14 \\
(11.9 \%)\end{array}$ & 3.34 & 1.22104 \\
\hline I enjoyed how my instructor taught the simulation. & $\begin{array}{c}18 \\
(15.3 \%)\end{array}$ & $\begin{array}{c}9 \\
(7.6 \%)\end{array}$ & $\begin{array}{c}17 \\
(14.4 \%)\end{array}$ & $\begin{array}{c}56 \\
(47.5 \%)\end{array}$ & $\begin{array}{c}18 \\
(15.3 \%)\end{array}$ & 3.41 & 1.27527 \\
\hline $\begin{array}{l}\text { The teaching materials used in this simulation were } \\
\text { motivating and helped me to learn. }\end{array}$ & $\begin{array}{c}14 \\
(11.9 \%) \\
\end{array}$ & $\begin{array}{c}20 \\
(16.9 \%) \\
\end{array}$ & $\begin{array}{c}20 \\
(16.9 \%) \\
\end{array}$ & $\begin{array}{c}52 \\
(44.1 \%) \\
\end{array}$ & $\begin{array}{c}12 \\
(10.2 \%) \\
\end{array}$ & 3.23 & 1.20312 \\
\hline $\begin{array}{l}\text { The way my instructor(s) taught the simulation was } \\
\text { suitable to the way I learn. }\end{array}$ & $\begin{array}{c}21 \\
(17.8 \%)\end{array}$ & $\begin{array}{c}11 \\
(9.3 \%)\end{array}$ & $\begin{array}{c}20 \\
(16.9 \%)\end{array}$ & $\begin{array}{c}49 \\
(41.5 \%)\end{array}$ & $\begin{array}{c}17 \\
(14.4 \%)\end{array}$ & 3.25 & 1.32166 \\
\hline $\mathbf{M} \pm$ SD & \multicolumn{7}{|c|}{$3.274 \pm 1.272514$} \\
\hline \multicolumn{8}{|l|}{ Self-confidence in current clinical simulation } \\
\hline $\begin{array}{l}\text { I am confident that I am mastering the content of the } \\
\text { simulation activity that my instructors presented. }\end{array}$ & $\begin{array}{c}18 \\
(15.3 \%)\end{array}$ & $\begin{array}{c}10 \\
(8.5 \%)\end{array}$ & $\begin{array}{c}20 \\
(16.9 \%)\end{array}$ & $\begin{array}{c}48 \\
(40.7 \%)\end{array}$ & $\begin{array}{c}22 \\
(18.6 \%)\end{array}$ & 3.39 & 1.23827 \\
\hline $\begin{array}{l}\text { I am confident that this simulation covered the } \\
\text { critical content necessary for the mastery of all } \\
\text { aspects of the nursing curriculum. }\end{array}$ & $\begin{array}{c}15 \\
(12.7 \%)\end{array}$ & $\begin{array}{c}18 \\
(15.3 \%)\end{array}$ & $\begin{array}{c}14 \\
(11.9 \%)\end{array}$ & $\begin{array}{c}57 \\
(48.3 \%)\end{array}$ & $\begin{array}{c}14 \\
(11.9 \%)\end{array}$ & 3.31 & 1.23827 \\
\hline $\begin{array}{l}\text { I am confident that I am developing the skills and } \\
\text { obtaining the required knowledge from this } \\
\text { simulation to perform the necessary tasks in a } \\
\text { clinical setting. }\end{array}$ & $\begin{array}{c}16 \\
(13.6 \%)\end{array}$ & $\begin{array}{c}11 \\
(9.3 \%)\end{array}$ & $\begin{array}{c}17 \\
(14.4 \%)\end{array}$ & $\begin{array}{c}60 \\
(50.8 \%)\end{array}$ & $\begin{array}{c}14 \\
(11.9 \%)\end{array}$ & 3.38 & 1.21894 \\
\hline $\begin{array}{l}\text { My instructors used helpful resources to teach the } \\
\text { simulation. }\end{array}$ & $\begin{array}{c}17 \\
(14.4 \%)\end{array}$ & $\begin{array}{c}12 \\
(10.2 \%)\end{array}$ & $\begin{array}{c}17 \\
(14.4 \%)\end{array}$ & $\begin{array}{c}53 \\
(44.9 \%)\end{array}$ & $\begin{array}{c}19 \\
(16.1 \%)\end{array}$ & 3.38 & 1.21894 \\
\hline $\begin{array}{l}\text { It is my responsibility as the student to learn what } \mathrm{I} \\
\text { need to know from this simulation activity. }\end{array}$ & $\begin{array}{c}14 \\
(11.9 \%)\end{array}$ & $\begin{array}{c}11 \\
(9.3 \%)\end{array}$ & $\begin{array}{c}13 \\
(11 \%)\end{array}$ & $\begin{array}{c}62 \\
(52.5 \%)\end{array}$ & $\begin{array}{c}18 \\
(15.3 \%)\end{array}$ & 3.50 & 1.21071 \\
\hline $\begin{array}{l}\text { I know how to get help when I do not understand the } \\
\text { concepts covered in the simulation. }\end{array}$ & $\begin{array}{c}13 \\
(11 \%)\end{array}$ & $\begin{array}{c}11 \\
(9.3 \%)\end{array}$ & $\begin{array}{c}15 \\
(12.7 \%) \\
\end{array}$ & $\begin{array}{c}62 \\
(52.5 \%) \\
\end{array}$ & $\begin{array}{c}17 \\
(14.4 \%)\end{array}$ & 3.50 & 1.18213 \\
\hline $\begin{array}{l}\text { I know how to use simulation activities to learn the } \\
\text { critical aspects of these skills. }\end{array}$ & $\begin{array}{c}17 \\
(14.4 \%)\end{array}$ & $\begin{array}{c}12 \\
(10.2 \%)\end{array}$ & $\begin{array}{c}13 \\
(11 \%)\end{array}$ & $\begin{array}{c}63 \\
(53.4 \%)\end{array}$ & $\begin{array}{c}13 \\
(11 \%)\end{array}$ & 3.36 & 1.23804 \\
\hline $\begin{array}{l}\text { It is the instructor's responsibility to tell me what I } \\
\text { need to learn about the simulation activity content } \\
\text { during class time. }\end{array}$ & $\begin{array}{c}16 \\
(13.6 \%)\end{array}$ & $\begin{array}{c}11 \\
(9.3 \%)\end{array}$ & $\begin{array}{c}11 \\
(9.3 \%)\end{array}$ & $\begin{array}{c}59 \\
(50 \%)\end{array}$ & $\begin{array}{c}21 \\
(17.8 \%)\end{array}$ & 3.49 & 1.27263 \\
\hline $\mathbf{M} \pm$ SD & \multicolumn{7}{|c|}{$3.41 \pm 1.227241$} \\
\hline \multicolumn{6}{|c|}{ Overall scale mean } & \multicolumn{2}{|c|}{$3.36 \pm 1.15$} \\
\hline
\end{tabular}

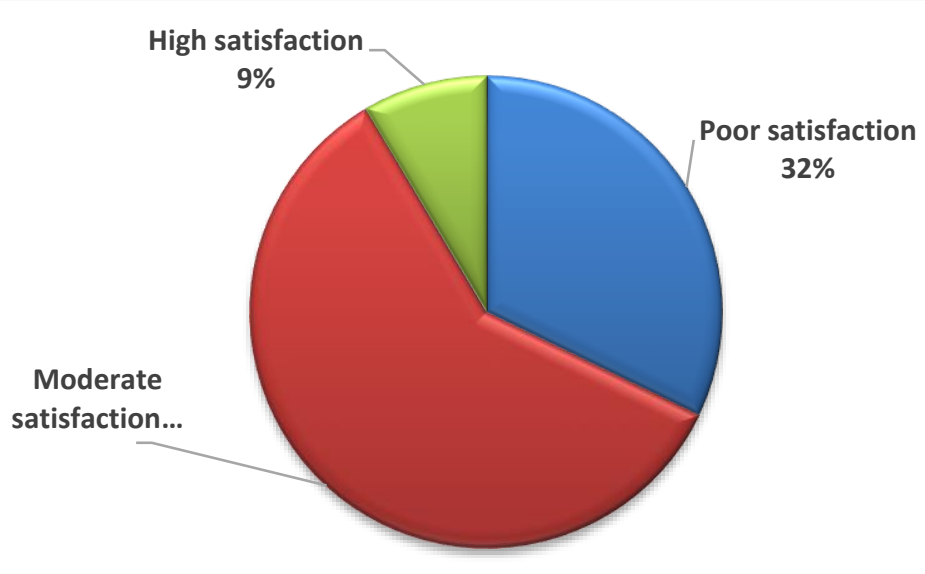

$\square$ Poor satisfaction $\square$ Moderate satisfaction $\square$ High satisfaction

Figure 5: Nursing students' perception of clinical simulation satisfaction levels 


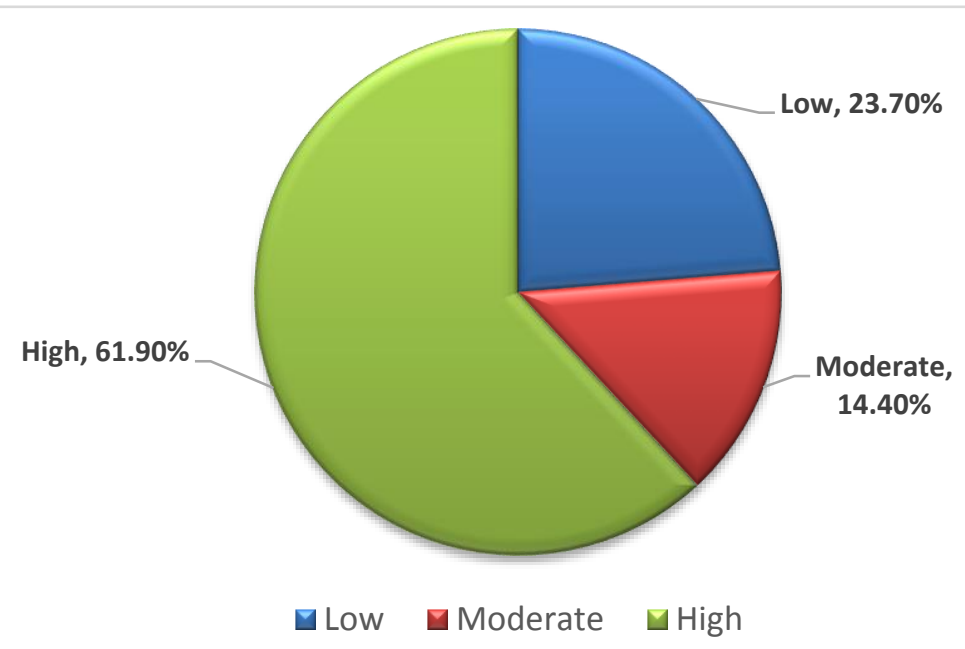

Figure 6: Nursing students' perception of clinical simulation self-confidence levels

Table 3: Relation between students' demographics data with simulation design, educational practices, and satisfaction/self-confidence

\begin{tabular}{|c|c|c|c|c|c|}
\hline \multicolumn{3}{|c|}{ Demographic data } & $\begin{array}{c}\text { Simulation } \\
\text { Design } \\
\text { Scale (SDS) }\end{array}$ & $\begin{array}{c}\text { Educational } \\
\text { Practices } \\
\text { Questionnaire } \\
\text { (EPQ) }\end{array}$ & $\begin{array}{c}\text { Student } \\
\text { Satisfaction- } \\
\text { Self-Confidence } \\
\text { in Learning } \\
\text { (SSSCL) }\end{array}$ \\
\hline Age & $\begin{array}{c}<20 \\
20-<25 \\
25 \geq\end{array}$ & $\begin{array}{c}\mathrm{r} \\
\text { P. value }\end{array}$ & $\begin{array}{l}0.009 \\
0.925\end{array}$ & $\begin{array}{l}0.018 \\
0.847\end{array}$ & $\begin{array}{l}0.041 \\
0.663\end{array}$ \\
\hline Marital status & $\begin{array}{l}\text { Single } \\
\text { Married }\end{array}$ & $\begin{array}{c}r \\
\text { P-value }\end{array}$ & $\begin{array}{l}0.027 \\
0.775\end{array}$ & $\begin{array}{l}0.041 \\
0.656\end{array}$ & $\begin{array}{l}0.047 \\
0.612\end{array}$ \\
\hline Academic year & $\begin{array}{c}\text { Freshmen } \\
\text { Sophomore } \\
\text { Junior } \\
\text { Senior } \\
\text { Internship }\end{array}$ & $\begin{array}{c}\mathrm{r} \\
\text { P-value }\end{array}$ & $\begin{array}{l}0.034 \\
0.716\end{array}$ & 0.0430 .643 & $\begin{array}{l}0.016 \\
0.867\end{array}$ \\
\hline Academic level & $\begin{array}{l}\text { Second } \\
\text { Third } \\
\text { Fourth } \\
\text { Fifth } \\
\text { Sixth } \\
\text { Seventh }\end{array}$ & $\begin{array}{c}r \\
\text { P-value }\end{array}$ & $\begin{array}{l}0.102 \\
0.270\end{array}$ & $\begin{array}{c}-0.127 \\
0.171\end{array}$ & $\begin{array}{l}0.097 \\
0.295\end{array}$ \\
\hline GPA & $\begin{array}{c}<2 \\
2-<3 \\
3-<4 \\
4 \geq \\
\end{array}$ & $\begin{array}{c}\mathrm{r} \\
\text { P-value }\end{array}$ & $\begin{array}{l}0.086 \\
0.354\end{array}$ & $\begin{array}{l}0.099 \\
0.287\end{array}$ & $\begin{array}{l}0.047 \\
0.613\end{array}$ \\
\hline $\begin{array}{c}\text { No. of students in } \\
\text { clinical simulation (lab } \\
\text { or virtual) }\end{array}$ & $\begin{array}{c}<15 \\
15-20 \\
20 \geq \\
\end{array}$ & $\begin{array}{c}\mathrm{r} \\
\mathrm{P}-\mathrm{value}\end{array}$ & $\begin{array}{l}0.002 \\
0.985\end{array}$ & 0.0250 .790 & $\begin{array}{l}0.047 \\
0.613\end{array}$ \\
\hline $\begin{array}{l}\text { No. of studied Courses } \\
\text { via simulation }\end{array}$ & $\begin{array}{c}<5 \\
5-<10 \\
10 \geq\end{array}$ & $\begin{array}{c}\mathrm{r} \\
\mathrm{P} \text {-value }\end{array}$ & $\begin{array}{l}0.001 \\
0.990\end{array}$ & 0.0100 .913 & $\begin{array}{l}0.002 \\
0.983\end{array}$ \\
\hline
\end{tabular}


Table 4: Correlation between nursing students' perceptions of simulation design, educational practices, and student satisfaction/self-confidence in learning

\begin{tabular}{|c|c|c|c|}
\hline Variables & $\begin{array}{c}\text { Simulation } \\
\text { Design Scale } \\
\text { (SDS) }\end{array}$ & $\begin{array}{c}\text { Educational Practices } \\
\text { Questionnaire } \\
\text { (EPQ) }\end{array}$ & $\begin{array}{c}\text { Student Satisfaction / } \\
\text { Self-Confidence in } \\
\text { Learning (SSSCL) }\end{array}$ \\
\hline $\begin{array}{c}\text { Simulation Design } \\
\text { Scale (SDS) }\end{array}$ & 1 & & \\
\hline $\begin{array}{c}\text { Educational Practices } \\
\text { Questionnaire } \\
\text { (EPQ) }\end{array}$ & $\begin{array}{c}0.914^{* *} \\
0.000\end{array}$ & 1 & 1 \\
\hline $\begin{array}{c}\text { Student Satisfaction / Self- } \\
\text { Confidence in Learning } \\
\text { (SSSCL) }\end{array}$ & $\begin{array}{c}0.808^{* *} \\
0.000\end{array}$ & $\begin{array}{c}0.902^{* * *} \\
0.000\end{array}$ & \\
\hline$* * *$ Correlation is significant at the $\mathrm{p}<.001$ level (2-tailed & & \\
\hline
\end{tabular}

Discussion

The intensity and bulk of the COVID-19 pandemic health problem have enforced nurse educators to revise how to educate new generations of nurses' students and tried to find out new alternatives for working directly with patients. Consequently, nurse leaders have stepped up to guarantee that learning educational milestones are achieved while ensuring the health and safety of patients.

It necessitates the academics to keep up-to-date with advances technologies of simulation-based learning to stay on right track for completion. Thereby, this research aimed to identify the elements of simulation design and educational practices in clinical simulation-based learning, which are associated with nursing students' satisfaction and self-confidence in managing simulation activities.

The current study findings illuminated that the students perceived the feedback/guided reflection subscale as the most prominent element of simulation design, followed by the support element, then the objectives and information element, and after that the problem-solving element. These findings mean that the majority of nursing students perceived feedback of clinical simulation as a constructive strategy for obtaining guidance on time and a chance for analyzing their behaviors and actions.

Additionally, the students suggested that the support subscale was perceived as the second noticeable element of simulation design. In this crisis of COVID-19, these results may be attributable to the flexibility of faculty members in asking questions, which permitting immediate response from the student, interaction with the teacher, and allowed clarifications of any misinterpretations during the feedback and support phases of clinical simulation design. 


\section{Tanta Scientific Nursing Journal}

In the same scene, the results showed that the fidelity (realism) element of clinical simulation design was perceived as the weakest mean score. This result was logical and reasonable to be observed during this time due to nursing students' isolation from studying at college and lack of interactions with their facilitators and peers.

In this context, the study's findings of Kada $(2018)^{[17]}$ showed that the magnitude of fidelity and feedback play a major role during the implementation of simulation experience. In another study, Najjar, Lyman, \& Miehl (2015) ${ }^{[24]}$ findings highlighted fidelity as the dominant theme arisen during the analysis of the emotional process of clinical simulation among baccalaureate nursing students, where they experienced frustration or inhibition when assigned to low levels of fidelity, while the high level of fidelity met their expectations during the simulation experience.

These findings were in the same line with Aebersold (2018) ${ }^{[8]}$, Ma (2013) ${ }^{[13]}$, and Winum (2017) ${ }^{[25]}$ findings who found out that feedback is an essential strategy for learners to understand the purpose and prioritize their reflection of decisions and provide them with freedom in making mistakes or asking questions. As well, it is a crucial theme for facilitators to keep them follow the high standard for doing the best.
In this aspect, Tosterud $(2015)^{[26]}$ conducted a study on 300 bachelor nursing students from different educational level to investigate their experiences with simulation as a learning approach in various conditions, the students elicited their preference for using the familiar and traditional approaches (paper and pen) than using the more advanced technologies for learning in simulation.

On another scene, the current study revealed that the observable feature of educational practice in the simulation was collaboration, followed by high expectations, then using diverse ways of learning, and finally active learning. The logical analysis of these results maybe because of the stressful situation of COVID19 , where the students felt collaboration and high expectations than active learning. On the contrary, Tosterud (2015) ${ }^{[26]}$ stated that active learning is a systematic and comprehensive feature for simulation-based learning.

Additionally, Olaussen, Heggdal, \& Tvedt (2020) $)^{[27]}$ argued that active learning and collaboration are essential intrinsic structures of simulation educational practice and the students have a big chance to be engaged actively by using their whole body, as well as the students had the ability to use all their five senses associated with their 


\section{Tanta Scientific Nursing Journal}

intellectual, psychological and interactional skills during the simulation session.

Furthermore, it was apparent from current findings that the highest percent of nursing students felt the presence of design elements during simulation experience, while more than half of them did not feel the presence of educational practice elements. This finding owing to a stressful environment in which the nursing students missing the facilitators' interaction and responding to their emerging needs during the simulation experience.

Moreover, the nursing students had increasing anxiety levels, lacking involvement, and motivation due to unexpected circumstances. This finding opposite to Brasil, Ribeiro, et al (2018) ${ }^{[28]}$ result, which showed overall good values of simulation design components.

As well, it is noteworthy that slightly more than half of the nursing students had a moderate level of satisfaction, while the highest percentage of them felt selfconfidence. In this context, Brasil, Ribeiro, et al (2018) ${ }^{[28]}$ and Souza, Santos, et al. $(2020)^{[29]}$ confirmed that the nursing students had high levels of satisfaction and self-confidence during clinical simulation experiences. In this scene, the highest percentage of students were satisfied with enjoying how their instructor taught the simulation, encouraging it as a variety of learning materials in all aspects of the nursing curriculum and preferring it as a way of learning. While the least items of satisfaction assigned to the simulation as a motivating, helping, and effective way of learning.

On the other side, the students felt confident of knowing how to get help when they do not understand the concepts covered in the simulation, learning what they need to know from this activity, aware that the need to learn for the simulation is the instructor's responsibility during class time, and mastering the content of this activity. Similarly, these findings were congruent with Omer $(2016)^{[19]}$ and Cant \& Cooper $(2017)^{[30]}$ findings. Furthermore, Ahmed, Hassan \& Mehany (2019) ${ }^{[18]}$ found that, the students in the simulation group had a substantially higher level of critical thinking, satisfaction and self-confidence relative to those in the control group.

In this regard, Hart, Spira, \& Moreno, (2014) ${ }^{[31]}$ stated that the high level of self-confidence and satisfaction in nurse students' abilities helps them to perform an effective intervention, recognizes errors, and participates as an effective team member to conduct. A Spanish study conducted by Jiménez, Torres, et al. $(2020)^{[1]}$ to analyze the nursing students' 


\section{Tanta Scientific Nursing Journal}

satisfaction and perceptions concerning the adaptation of simulation-based education during the period of the COVID-19 pandemic, the study revealed a high level of satisfaction and positive perceptions regarding the innovative strategy of simulated nursing video consultations.

According to students' responses, the present findings found no statistically significant differences between their sociodemographic data and all items of simulation design, educational practices, and student satisfaction-self-confidence in learning. These results were contradicted with Omer $(2016)^{[19]}$ findings who demonstrated a statistically significant correlation between students' satisfaction with their age and number of courses. While no statistically significant correlation has seemed between students' demographic data and self-confidence outcome.

The results' analysis elicited that experiencing accurate feedback; enough support, clear objectives and information, and showing problem-solving abilities of simulation design were significantly correlated with collaboration, high expectations, diverse ways of learning, and active learning of simulation educational practices.

Moreover, the results indicated that experiencing accurate feedback, enough support, clear objectives, and information, and problem solving of simulation design were significantly associated with nursing students' satisfaction and self-confidence during the conducting of simulation activity even with a low level of fidelity. The experience of receiving more support from facilitators resulted in a higher level of satisfaction and self-confidence.

These findings indicated the essentiality of educational practices and design elements during simulation sessions and the presence of interference among these factors. As well, practicing collaboration, high expectations, diverse ways of learning, and active learning during educational practices of the simulation were significantly correlated with nursing students' satisfaction and self-confidence during simulation activity.

In this aspect, Olaussen, Heggdal, Tvedt (2020) $)^{[27]}$ identified that the experience of having less support in simulation design from facilitators resulted in greater self-confidence. Active learning of educational practice is an important element to achieve students' self-confidence and satisfaction while learning objectives and information components of simulation design were positively associated with students' self-confidence during managing simulation activity. 


\section{Tanta Scientific Nursing Journal}

While, the American study of Kada (2018) $)^{[17]}$ confirmed the absence of a statistically significant relationship between associate degree nursing students' selfconfidence in learning and their perception of the presence of five instructional design components (objectives and information, support, problem-solving, feedback/guided reflection, and fidelity/realism) in a highfidelity simulator learning experience.

\section{Conclusion:}

In conclusion, the current study's findings indicated that the presence of design elements and educational practices' features of clinical simulation-based learning are imperative tools for achieving success. Around half of nursing students had a low level of satisfaction with simulation activity and the highest percent of them had a high level of self-confidence for managing the simulated situations.

There were no statistically significant differences between students' sociodemographic data and all elements of simulation design, educational practices, and student satisfaction/self-confidence in learning. Moreover, statistically significant correlations were apparent between all elements of simulation design and educational practices of simulation sessions, as well as between simulation design and student satisfaction/self-confidence in learning. Furthermore, there were significant correlations between elements of educational practices and student satisfaction-self-confidence in learning.

\section{Recommendations:}

Based on the aforementioned current study's findings, the researchers recommended the following:

- Encouragement of the nursing colleges to allocate budget for purchasing equipment and high fidelity patient simulation manikins to adapt to local and international challenges facing nursing education.

- Incorporating the virtual clinical simulation and other adaptive digital learning methods as a teaching strategy that should be shifted to use effective technology in nursing curricula for finding out new alternative learning styles for practicum courses of nursing and nonnursing specialties, starting from freshmen to senior year.

- Developing comprehensive training programs for nursing educators in different specialties to learn effectively how to design, practice, and debrief simulation-based experiences for meeting the intended learning outcomes of the nursing syllabus.

- Develop further quantitative researches to evaluate the learning outcomes of using 
high-fidelity simulation experiences among a large sample of nursing students and faculty educators.

\section{References}

1. Jiménez Rodríguez D., Torres Navarro M.d.M., Plaza del Pino F. and Arrogante Maroto O. (2020). Simulated Nursing Video Consultations: An Innovative Proposal during Covid-19 Confinement, Clinical Simulation in Nursing, doi.org/10.1016/j.ecns.2020.08.004.

2. Huang C., Wang, Y., Li, X., Ren, L., Zhao, J., Hu, Y., ..., \& Cheng, Z. (2020). Clinical features of patients infected with 2019 novel coronavirus in Wuhan, China. The Lancet, 395(10223), 497506. doi:10.1016/S01406736(20)30183-5.

3. Dewart G., Corcoran L., Thirsk L., Petrovic K. (2020). Nursing education in a pandemic: Academic challenges in response to COVID-19.Nurse Education Today, 92: 104471.

4. Park K., Ahn Y., Kang N., Sohn M. (2016). Development of a simulation based assessment to evaluate the clinical competencies of Korean nursing students. Nurse Educ Today.36:337-41. doi:10.1016/j.nedt.2015.08.020.

5. Martins J. (2017). Learning and development in the context of simulated practice. Rev. Enf. Ref. IV(12):155-62.
155-162. $\quad$ http://dx.doi.org/10.12707/ RIV16074.

6. Nyback M. H., Vikström I. (2017). Active Learning Methods in Nursing Education - A New Paradigm? Athens Journal of Health, 4(4): 281-302.

7. Hayden J, Gross L, and Smiley R. (2014). Simulation in Nursing Education: Current Regulations and Practices. Journal of Nursing Regulation. 5: 25-30.

8. Aebersold M., (2018). Simulation Based Learning: No Longer a Novelty in Undergraduate Education. OJIN: The Online Journal of Issues in Nursing Vol. 23, No. 2.

9. Liaw S., Chan S., and Siau C. (2014). Comparison of Virtual Patient Simulation with Mannequin-Based Simulation for Improving Clinical Performances in Assessing and Managing Clinical Deterioration: Randomized Controlled Trial. Journal of Medical Internet Research. Available from: http://www.jmir.org/ 2014/ 9/e214/.

10. Sundler A. J., Pettersson A., and Berglund M. (2015). Undergraduate nursing students' experiences when examining nursing skills in clinical simulation laboratories with highfidelity patient simulators: A 
phenomenological research study. Nurse Educ Today; 25. doi:10.1016/j.nedt. 2015.04.008.

11. Cremonini V., Ferri P., Artioli G., Sarli L., Piccioni E., Rubbi I. (2015). Nursing students' experiences of and satisfaction with the clinical learning environment: the role of educational models in the simulation laboratory and in clinical practice. Acta Biomed for Health Professions; Vol. 86, S. 3: 194204. Available at: https://www.semanticscholar.org/paper/ Nursing-students'-experiences-of-and$\underline{\text { satisfaction-Cremonini- }}$

Ferri/8aba91d45ad2fe0ff4d7393b4eddf e5ec974e71d

12. Jeffries P. R., Dreifuerst, T. K., Kardong-Edgren S., and Hayden J. (2015). Faculty Development When Initiating Simulation Programs: Lessons Learned From the National Simulation Study, 5(4): 17-23.

13. Ma Xiaoying (2013). BSN Students' Perception of Satisfaction and Selfconfidence after a Simulated Mock Code Experience: A Descriptive Study". Master of Science in Nursing Theses. 2. http://digitalcommons.cedarville.edu/nu rsing theses/2

14. Fawaza M. A., Hamdan-Mansourb A. M., Tass A. (2018). Challenges facing nursing education in the advanced healthcare environment. International Journal of Africa Nursing Sciences 9: 105-110.

15. Jeffries P. R., Rodgers B., and Adamson K. (2015). NLN Jeffries Simulation Theory: Brief Narrative Description. Nursing Education Perspectives, 36(5):292 - 293. Available at: https://case.edu/nursing/postgrad/sites/c ase.edu.nursing/files/2018-

\section{5/Simulation-Theory-Jeffries-}

\section{Theory.pdf.}

16. Jeffries P. R. (2012). Simulations in nursing education: From conceptualization to evaluation ( $2^{\text {nd }} e d$.): National League for Nursing. Lippincott Williams \& Wilkins, New York.

17. Kada G. (2018). Analysis of Relationship between Associate Degree Nursing Student's Self-Confidence in Learning and their Perceived Presence of Instructional Design Characteristics. COJ Nurse Healthcare, 1(3):67-73. doi:10.31031/COJNH.2018.01.000513.

18. Ahmed E. S., Hassan A. M. and Mehany M. M. (2019). Effect of simulation on critical thinking, satisfaction and selfconfidence of nursing students during care of pneumonic child. International Journal of Advance Research in 
Nursing. 2(1): 131-137. Available at: www.nursingjournal.net.

19. Omer T. (2016). Nursing Students' Perceptions of Satisfaction and Selfconfidence with Clinical Simulation Experience. Journal of Education and Practice, 7(5), 131-138. https://files. eric.ed.gov/fulltext/EJ1092418.pdf.

20. Baptista R. C., Martins J. C., Carneiro F. M., Mazzo A. (2014). Students' satisfaction with simulated clinical experiences: validation of an assessment scale. Rev. Latino-Am. Enfermagem, 22(5):709-15. 이:10.1590/0104$\underline{1169.3295 .2471 .}$.

21. Thompson S. K. (2012). Sampling, John Wiley \& Sons, Inc, $3^{\text {rd }}$ ed., 59-60.

22. National League for Nursing (NLN) (2006). Descriptions of available instruments. Retrieved from http:// www.nln.org/professionaldevelopmentprograms/research/toolsand-

instruments/descriptions-ofavailableinstruments, 2018.

23. Pimentel J. L. (2010): A note on the usage of Likert Scaling for research data analysis, USM R \& D. 18(2): 109112.

24. Najjar R. H., Lyman B., Miehl N. (2015). Nursing students' experiences with high-fidelity simulation. Int J Nurs Educ Scholarsh, 19(12): 14-21. doi:10.1515/ijnes-2015-0010.
25. Winum A. (2017). BSN Students' Satisfaction and Self-Confidence in Simulation-based Learning Undergraduate Honors Theses. 13.

26. Tosterud R. (2015). Simulation used as a learning approach in nursing education: Students' experiences and validation of evaluation questionnaires.

Karlstad University Studies, Dissertation, 1. http://www.divaportal.org/smash/get/diva2:760893/fullt ext01.pdf

27. Olaussen C. Heggdal K., Tvedt C. R. (2020). Elements in scenario _ based simulation associated with nursing students' self-confidence and satisfaction: A cross _ sectional study. Nursing Open. 7:170-179. doi:10. 1002/nop2.375.

28. Brasil G. C., Ribeiro L. M., Mazzo A., Almeida R. G., et al. (2018). Use of the design and self-confidence scales in the assessment of maternal-child realistic simulation. Revista de Enfermagem Referência. (19):117 - 26.

29. Souza C., Santos W., Salgado P., Prado J. P., Toledo L., Paiva L. (2020). Evaluating the "satisfaction" and "selfconfidence" in nursing students in undergoing simulated clinical experiences. Rev Esc Enferm USP. 54:(e03583). 
30. Cant R. P., \& Cooper S. J. (2017). Use of simulation-based learning in undergraduate nurse education: An umbrella systematic review. Nurse Education Today. 49, 63-71. doi.org/10.1016/j.nedt.2016.11.015.

31. Hart P., Spira L., and Moreno N. (2014). Psychometric properties of clinical decision-making self-confidence scale. Journal of Nursing Management. 22: 312-322. http://dx.doi.org/10.1891/10613749.22. 2.312. 